\title{
CASTLEMAN'S DISEASE OF THE NECK IN A CHILD: A RARITY
}

\author{
K. Mahesh Kumar¹, Kazi Wajid Husain², K. Sai Sindhu³, J. Anunayi ${ }^{4}$
}

\section{HOW TO CITE THIS ARTICLE:}

K. Mahesh Kumar, Kazi Wajid Husain, K. Sai Sindhu, J. Anunayi. “Castleman's disease of the neck in a child: a rarity". Journal of Evolution of Medical and Dental Sciences 2014; Vol. 3, Issue 08, February 24;

Page: 1940-1945, DOI: 10.14260/jemds/2014/2084

ABSTRACT: Castleman's disease is a benign lymphoproliferative disorder of an unknown aetiology, occurring rarely in the paediatric population. It primarily occurs at the sites like chest, abdomen and infrequently in the neck. We report a very rare case of Castleman's disease in an 8-year-old boy presenting with a localised mass in the right neck region. The child complained of vague clinical symptoms and local examination revealed a soft, non-tender and immobile mass in the right neck. Laboratory studies were non-contributory. Ultrasonography of the head and neck helped in defining the neck mass, although the findings were non-specific. The mass was surgically excised and subjected to pathological examination. Histopathological assessment was consistent with Castleman's disease, hyaline-vascular type. Follow up studies for a period of 6-months showed no evidence of recurrence of the lesion.

KEYWORDS: Castleman's disease, child, neck mass, hyaline-vascular.

BACKGROUND: Castleman's disease is a rare lymphoproliferative disorder of an unknown aetiology with its first description dating back to $1954^{1-2}$. Since then, many theories have been postulated to establish its aetiology with one theory suggesting the role of immune reaction to viral infections, while the other implicates interleukin 62-4. In children, the disease primarily occurs at the sites like chest, abdomen and very rarely in the neck ${ }^{5}$. It usually presents as a solitary mass when it occurs in the neck ${ }^{6}$. The disease is categorised as unicentric, if it remains localised to only one lymph-node group and multicentric, if it disseminates towards two or more lymph-node groups ${ }^{7}$ Histopathologically, Castleman's disease is sub-classified into hyaline-vascular, plasma cell and mixed types $^{3}$. We report a very rare case of Castleman's disease, hyaline-vascular type in an 8-year-old boy presenting with a localised right neck mass.

CASE REPORT: An 8-year-old boy presented to the outpatient department with a 6-months history of painless mass in the right neck region associated with low-grade fever, excessive sweating, fatigue and unexplained weight loss. There was also a history of vomiting thrice in last two weeks. The General physical examination was normal. Systemic examination was within normal limits. On local examination, the mass on the right side of the neck measured approximately $4 \mathrm{~cm} \times 3.5 \mathrm{~cm}$ and was soft, non-tender and immobile, with skin overlying the mass being normal (Figure $1 \mathrm{~A}$ and $\mathrm{B}$ ). 


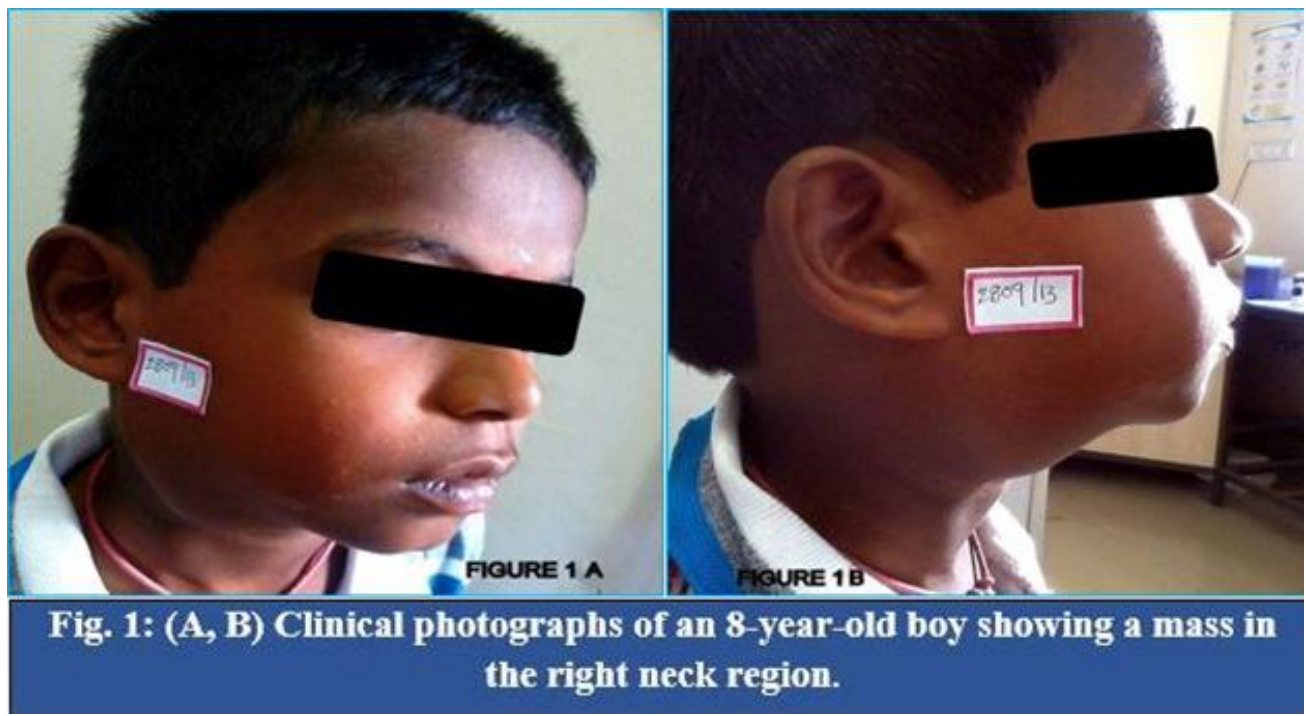

Routine laboratory investigations like complete blood picture, urine examination, were within normal ranges. Mantoux test was non-reactive. Radiological investigations, which included chest radiograph was normal. Ultrasonography of the head and neck revealed a homogenous, hypoechoic mass with increased vascularity measuring approximately $3.5 \mathrm{~cm} \times 2.8 \mathrm{~cm} \times 1 \mathrm{~cm}$ in the right cervical region. Ultrasonography of the abdomen revealed no abnormality ruling out the multicentric, disseminated disease. Smears from fine needle aspiration of the mass lesion predominantly showed small and large lymphocytes, tingible body macrophages admixed with fibrotic strands in haemorrhagic background (Figure $2 \mathrm{~A}$ and B). There was no evidence of malignancy. A cytological diagnosis of non-specific lymphadenitis was made and biopsy advised to arrive at definite opinion.

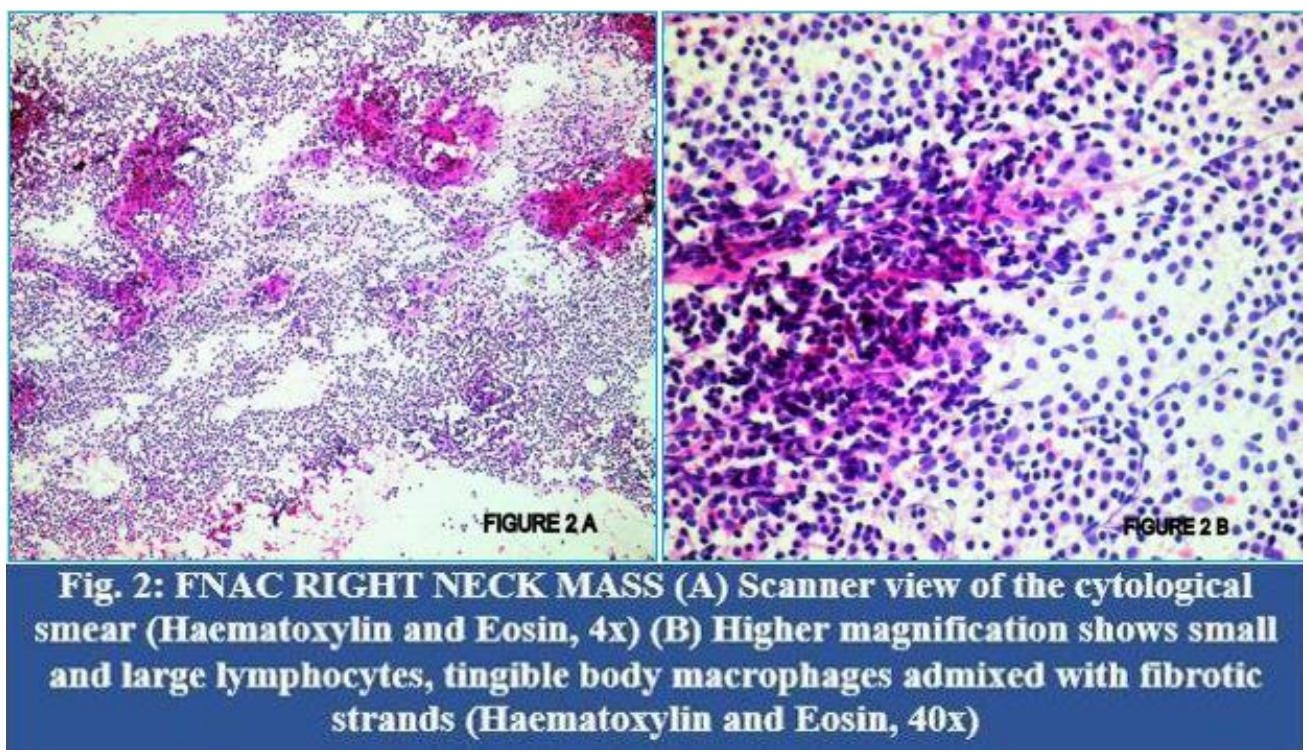


The neck mass was surgically excised and biopsy specimen sent to the department of pathology for gross examination and histopathological assessment. The post-operative period remained uneventful and 6-month follow-up period showed no evidence of the disease progression or recurrence.

\section{PATHOLOGY FINDINGS:}

Gross Examination: Grossly, the specimen of excision biopsy was a single lymph node measuring 3.5 $\mathrm{cm} \times 3 \mathrm{~cm}$ x $1 \mathrm{~cm}$ (Figure $3 \mathrm{~A}$ ). Cut section was fleshy and showed homogenous, grey white areas with foci peripherally showing a grey brown area. No areas of haemorrhage or necrosis were documented (Figure 3 B).

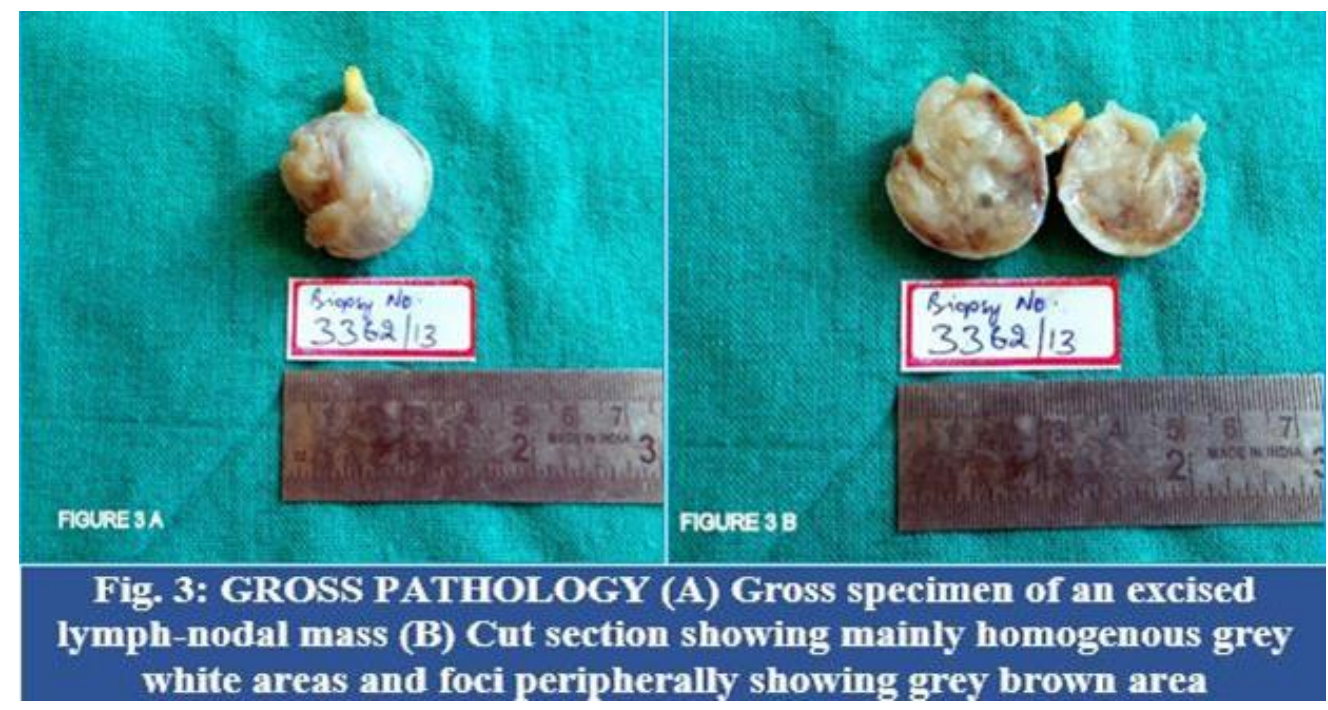

MICROSCOPY: Histopathological examination revealed lymphatic tissue having numerous germinal centres with central fibrosis and marked vascularisation. (Figure 4 A, B and C) Some lymphoid follicles showed germinal centres with concentric onion skin-like layering of surrounding lymphoid cells (Figure 4 D). There were numerous proliferating blood vessels. Based on these findings the lesion was diagnosed as Castleman's disease, hyaline vascular type. 


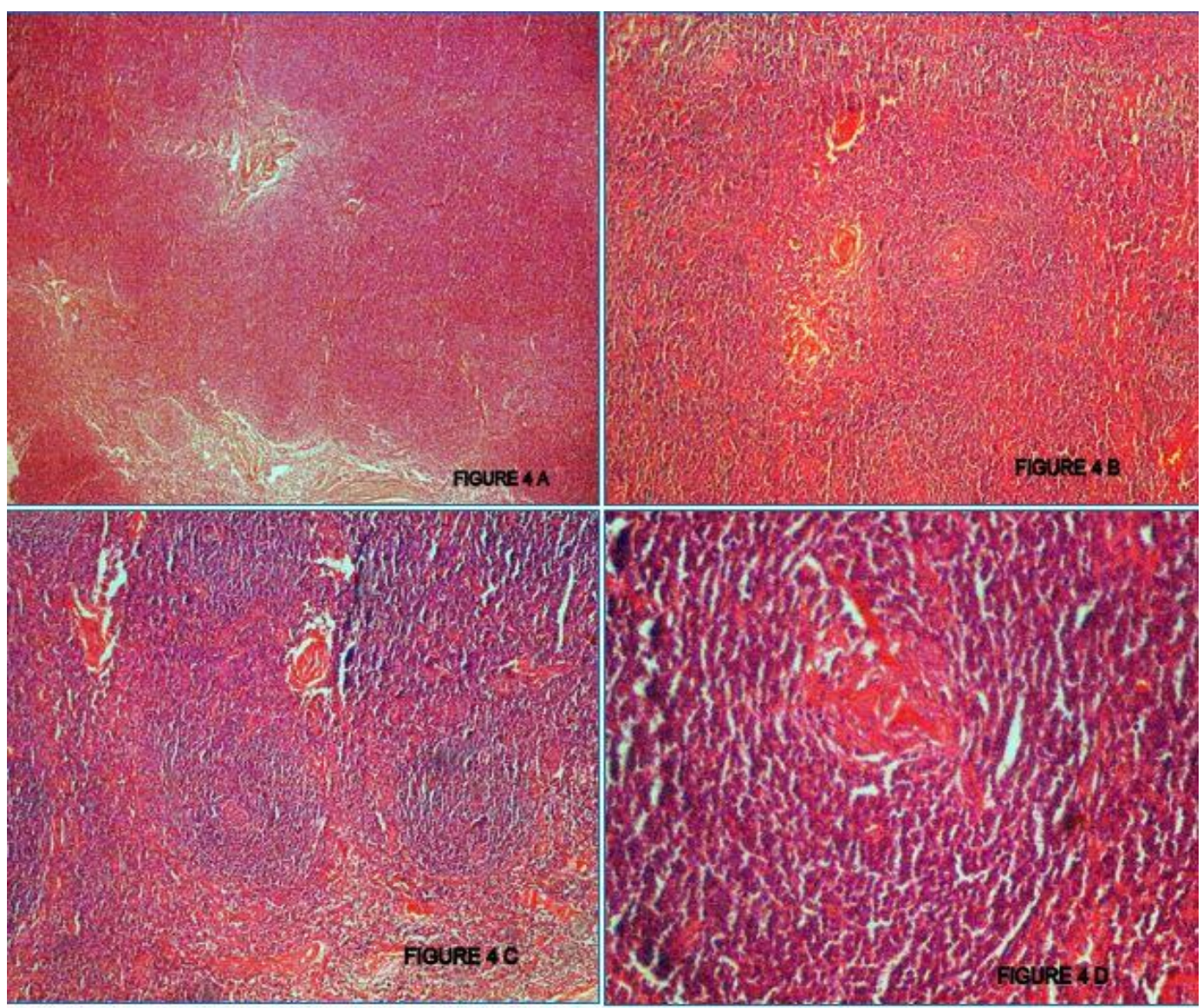

Fig. 4: CASTLEMAN'S DISEASE, HYALINE-VASCULAR TYPE (A) Photomicrograph shows lymphatic tissue with numerous germinal centres (Haematoxylin and Eosin, $4 \mathbf{x}$ ) (B, C) Photomicrographs showing germinal centres with central fibrosis and marked vascularisation. (Haematoxylin and Eosin, 10x) (D) Photomicrograph of a lymphoid follicle showing germinal centre with concentric onion skin-like layering of surrounding lymphoid cells (Haematoxylin and Eosin, 40x)

DISCUSSION: Benjamin Castleman first described Castleman's disease in 1954 as a large mediastinal mass resembling thymoma ${ }^{8}$. It is a benign lymphoproliferative disease with various names like giant lymphoid hyperplasia, angiomatous lymphoid hamartoma, angiofollicular lymphoid hyperplasia, or giant benign lymphoma ${ }^{7}$.

Little is known about the aetiology of this uncommon lesion. One theory proposes Castleman's disease as an immune response to viral infection, although the viral cultures remain persistently negative and demonstration of Epstein-Barr virus; Human Herpes virus type 8 genome by polymerase chain reaction gives no inference whether the virus is responsible for the disease or associated with it. According to another theory, the pattern of interleukin 6 gene was consistently demonstrated in Castleman's disease and the levels of serum interleukin 6 correlated well with clinical and biological abnormalities ${ }^{4}$.

The estimated prevalence rates of Castleman's disease are 1 in 100,000 with a peak incidence in the $4^{\text {th }}$ decade of life. This disease commonly presents in the adults. Although the exact prevalence rates of this disease in paediatric population remains unknown, it is still very rare ${ }^{3}$. Yet, the literature shows about 100 published cases of paediatric Castleman's disease ${ }^{2}$. In children, the chest (33\%) is the commonest site of disease, followed by the abdomen (30\%), neck (23\%) and axilla (7\%) ${ }^{6}$. Neck 
mass is an uncommon presentation of this disease in paediatric population ${ }^{3}$. To our best knowledge, there are only 31 reported cases of paediatric Castleman's disease presenting with neck mass.

Clinically, a child with Castleman's disease usually remains asymptomatic or may present with non-specific symptoms with a neck mass, posing a diagnostic dilemma. Often, laboratory tests are normal. Ultrasonography, computed tomography and magnetic resonance imaging scan helps in delineating the lesion and extent of the disease. Fine needle aspiration of the lesion has its own limitations. Histopathological examination of the biopsy from the lesion helps in making a definitive diagnosis.

Treatment of the unicentric, localised disease involves surgical resection of the affected lymph node. Multicentric, disseminated disease needs medical treatment with steroids alone or in combination with agents like methotrexate, intravenous immunoglobulin or interferon. Plasmapheresis offers some success. ${ }^{1}$

CONCLUSION: Castleman's disease as a benign lymphoproliferative disease is a rare diagnosis in the paediatric population and the disease presenting as a neck mass is even rarer. Lesions in the paediatric age group present with a diagnostic dilemma and a high index of suspicion is necessary for its diagnosis, since clinical manifestations are often vague and laboratory findings non-contributory. Radiological investigations help in delineating the lesion but are inconclusive. Histopathology remains the main tool for the definitive diagnosis of the Castleman's disease supported by clinical details and follow-up.

\section{REFERENCES:}

1. Buesing K, Perry D, Reyes C, Abdessalam S. Castleman disease: surgical cure in pediatric patients. J Pediatr Surg. 2009 Jan; 44 (1): e5-8.

2. Farruggia P, Trizzino A, Scibetta N, Cecchetto G, Guerrieri P, D'Amore ES, D'Angelo P. Castleman's disease in childhood: report of three cases and review of the literature. Ital J Pediatr. 2011 Oct 20; 37:50.

3. Zawawi F, Varshney R, Haegert DG, Daniel SJ. Castleman's Disease: A rare finding in a pediatric neck. Int J Pediatr Otorhinolaryngol. 2014 Feb; 78 (2): 370-2.

4. Parez N, Bader-Meunier B, Roy CC, Dommergues JP. Paediatric Castleman disease: report of seven cases and review of the literature. Eur J Pediatr. 1999 Aug; 158 (8): 631-7.

5. Tan TY, Pang KP, Goh HK, Teo EL, Abhilash B, Walford N. Castleman's disease of the neck: a description of four cases on contrast-enhanced CT. Br J Radiol. 2004 Mar; 77 (915): 253-6.

6. Zhong LP, Chen GF, Zhao SF. Cervical Castleman disease in children. British Journal of Oral and Maxillofacial Surgery.2004; 42 (1): 69-71.

7. Bouguila J, Lahmer I, Abdelkefi M, Affissath A, Trimeche M, Boughammoura L. Cervical unicentric Castleman's disease in children. Eur Ann Otorhinolaryngol Head Neck Dis. 2013 Mar 5; 130: 221-223.

8. Chen CC, Jiang RS, Chou G, Wang CP. Castleman's disease of the neck. J Chin Med Assoc, 2007; 70(12):556-558. 


\section{CASE REPORT}

\section{AUTHORS:}

1. K. Mahesh Kumar

2. Kazi Wajid Husain

3. K. Sai Sindhu

4. J. Anunayi

\section{PARTICULARS OF CONTRIBUTORS:}

1. Assistant Professor, Department of Pathology, Malla Reddy Institute of Medical Sciences, Hyderabad, Andhra Pradesh.

2. Assistant Professor, Department Of Pathology, Sri Venkateshwara Medical College, Hospital and Research Centre, Pondicherry.

3. Post Graduate, Department of Pathology, Osmania Medical College, Hyderabad, Andhra Pradesh.
4. Associate Professor, Department of Pathology, Osmania Medical College, Hyderabad, Andhra Pradesh.

\section{NAME ADDRESS EMAIL ID OF THE CORRESPONDING AUTHOR:}

Dr. K. Mahesh Kumar, Consultant Pathologist, H. No. 7-1-390, Flat No. 503, Sri Sai Residency, Balkampet, Sanjeeva Reddy Nagar, Hyderabad, Andhra Pradesh, India. E-mail: doctormaheshgoud@gmail.com

Date of Submission: 27/01/2014. Date of Peer Review: 28/01/2014. Date of Acceptance: 08/02/2014. Date of Publishing: 21/02/2014. 